\title{
Dispersal behaviour of African wild dogs in Kenya
}

Running head: $\quad$ African wild dog dispersal

Authors: $\quad$ Rosie Woodroffe ${ }^{1,2 *}$, D. Rabaiotti ${ }^{1,3}$, D.K. Ngatia ${ }^{2}$, Thomas R.C.

Smallwood ${ }^{1,4}$, Stefanie Strebel ${ }^{2,5}$, and Helen M.K. O'Neill1,3

Author affiliations: ${ }^{1}$ Insititute of Zoology, Regent's Park, London NW1 4RY, UK

${ }_{2}^{2}$ Mpala Research Centre, PO Box 555, Nanyuki, Kenya

${ }^{3}$ Centre for Biodiversity and Environment Research, University

College London, London WC1E 6BT, UK

${ }^{4}$ Department of Infectious Disease Epidemiology, London W2

1PG, UK

5Department of Evolutionary Biology and Environmental

Studies, University of Zurich, 8057 Zurich, Switzerland 


\begin{abstract}
Dispersal behaviour plays a key role in social organisation, demography, and population genetics. We describe dispersal behaviour in a population of African wild dogs (Lycaon pictus) in Kenya. Almost all individuals, of both sexes, left their natal packs, with 45 of 46 reproductively-active "alpha" individuals acquiring their status through dispersal. Dispersal age, group size, and distance did not differ between males and females. However, only females embarked on secondary dispersal, probably reflecting stronger reproductive competition among females than males. When dispersing, GPS-collared wild dogs travelled further than when resident, both in daylight and by night, following routes an order of magnitude longer than the straightline distance covered. Dispersers experienced a daily mortality risk three times that experienced by adults in resident packs. The detailed movement data provided by GPScollars helped to reconcile differences between dispersal patterns reported previously from other wild dog populations. However, the dispersal patterns observed at this and other sites contrast with those assumed in published demographic models for this endangered species. Given the central role of dispersal in demography, models of wild dog population dynamics need to be updated to account for improved understanding of dispersal processes.
\end{abstract}

Keywords: Conservation; Cooperative breeding; Dispersal; Lycaon; Mortality; Movement behaviour; Movement ecology; Survival. 


\section{Introduction}

Dispersal behaviour plays a key role in social behaviour, demography, and population genetics. In many species, dispersal is the primary route to reproductive success: individuals of one or both sexes must disperse to find unrelated mates or vacant territories (Pusey, 1987). However, individual dispersal decisions also have farreaching consequences for population processes. Dispersal patterns determine the structure of social groups, which can range from aggregations of unrelated individuals containing multiple potential mates (Macedo, Cariello, Graves, \& Schwabl, 2004), to closed family groups which avoid inbreeding only by extra-group mating (e.g., Pilot, Dahlheim, \& Hoelzel, 2010). Individuals' decisions to leave or join specific social groups influence group size, which can have pervasive impacts on the survival and reproductive success of other group members, ultimately contributing to population dynamics (e.g., Bateman, Ozgul, Coulson, \& Clutton-Brock, 2012; Ebensperger \& Hayes, 2008). Dispersers are often the animals that found new social groups (e.g., Nascimento, Nali, \& da Fonseca, 2014), and the animals left when groups disband (e.g. Stokes, Parnell, \& Olejniczak, 2003). Dispersing animals often travel relatively long distances (e.g., Fattebert, Dickerson, Balme, Slotow, \& Hunter, 2013), maintaining gene flow between sub-populations (e.g., Riley et al., 2014) and contributing to metapopulation persistence (e.g., Sutherland, Elston, \& Lambin, 2012).

While dispersal may contribute to population structure and persistence, it can also entail risks. Dispersers often travel through suboptimal habitat, and may thus experience higher mortality than resident animals (e.g., Newby et al., 2013). Such mortality can undermine metapopulation persistence, especially when habitat fragmentation extends the distances between habitable patches and increases mortality risks in the intervening matrix (e.g., Proctor et al., 2012). Dispersers can also contribute to disease transmission by carrying pathogens between subpopulations (e.g., Robertson, Chilvers, Duignan, Wilkinson, \& Gemmell, 2006).

The key role of dispersal behaviour in the population dynamics of social species means that demographic models for such species need to incorporate dispersal processes. Such models are especially important for endangered species, in which population modelling may be a vital method to assess extinction risks and to explore potential management interventions. Acquiring data to parameterise such models may be challenging, especially for long-lived species in which dispersal may be a rare event. 
Nevertheless, ignoring or misrepresenting social structure limits the predictive power of demographic and epidemiological models (Bateman, Coulson, \& Clutton-Brock, 2011; Craft, Hawthorne, Packer, \& Dobson, 2008; Zeigler \& Walters, 2014).

The African wild dog, Lycaon pictus, is a species which would benefit from such modelling. This globally endangered species in known to persist in just $7 \%$ of its historic range, and remaining populations are impacted by habitat loss, human-wildlife conflict, infectious disease, and climate change (Woodroffe \& Sillero-Zubiri, 2013). Conservation efforts could be greatly improved by addressing questions such as how much connectivity is needed to secure population viability, whether climate change impacts could be mitigated by reducing human-caused mortality, and whether disease risks can be reduced by vaccinating domestic dogs (O'Neill, Durant, \& Woodroffe, in review; Prager et al., 2013; Woodroffe, Groom, \& McNutt, 2017). All of these questions are amenable to population modelling but, if such models are to provide reliable conservation guidance, they must accurately account for wild dogs' social structure.

The African wild dog is a highly social species. Within each pack, reproduction is restricted mainly to a socially dominant "alpha” pair (Creel, Creel, Mills, \& Monfort, 1997), relying on alloparental care from other pack members to raise pups successfully (Malcolm \& Marten, 1982). Solitary reproduction is extremely infrequent (but see Woodroffe, Chapman, \& Lemusana, 2009). Because larger packs consistently raise larger litters (Creel, Mills, \& McNutt, 2004; Rasmussen, Gusset, Courchamp, \& Macdonald, 2008; Woodroffe et al., 2017), and may experience lower mortality (Woodroffe, O’Neill \& Rabaiotti (in press), but see Creel \& Creel (2015)), pack size has pervasive impacts on wild dog demography (Angulo, Rasmussen, Macdonald, \& Courchamp, 2013; Courchamp \& Macdonald, 2001; Woodroffe et al., in press).

Models of the demography of cooperative breeders suggest that both the behaviour and survival of dispersing individuals may have far-reaching consequences for population dynamics. If individuals seldom disperse from their natal groups, those groups are likely to grow large, whereas frequent dispersal, and high mortality of dispersers, could reduce average group size (Bateman, Ozgul, Krkosek, \& Clutton-Brock, 2018; Lerch, Nolting, \& Abbott, 2018), potentially impacting recruitment and survival within the population. Specific models of wild dog demography have represented dispersal in a variety of ways, for example assuming that subdominants typically inherit alpha status from their parents, or that dispersers frequently join other packs 
(Courchamp, Clutton-Brock, \& Grenfell, 2000; Gusset et al., 2009; Prager, Woodroffe, Cameron, \& Haydon, 2011; Vial, Cleaveland, Rasmussen, \& Haydon, 2006; Vucetich \& Creel, 1999). However, the empirical basis of these dispersal rules is often unclear.

Wild dogs typically disperse in groups, although emigration rates have been characterised as female-biased in northern Tanzania (Frame, Malcolm, Frame, \& van Lawick, 1979), male biased in northern Botswana (McNutt, 1996), and without detectable sex bias in southern Tanzania (Creel \& Creel, 2002). Given the potential role of dispersal rules in population dynamics (Woodroffe et al., in press), such geographic variation in dispersal patterns might influence demography in different parts of the species' range. Moreover, as dispersing wild dogs have been recorded travelling hundreds of kilometres (Davies-Mostert et al., 2012), traversing lands with greater human density than those occupied by resident packs (Jackson, Marnewick, Lindsey, Roskaft, \& Robertson, 2016; O'Neill et al., in review), dispersal-related mortality may be high, with additional consequences for demography.

To inform future modelling of African wild dog population dynamics, we characterised wild dog dispersal at a study site in Kenya. We explored differences in dispersal behaviour between males and females, comparing the consequences for survival and reproduction of dispersing versus remaining in the natal pack. We also investigated changes in movement behaviour associated with dispersal, which might help to explain variation in mortality risks.

\section{Methods}

Study site

Our study area covered Laikipia County $\left(37^{\circ} 2^{\prime} \mathrm{E}, 0^{\circ} 6^{\prime} \mathrm{N}, 1800 \mathrm{~m}\right.$ ASL, annual rainfall $590 \mathrm{~mm}$ ), and parts of neighbouring Samburu and Isiolo Counties, in northern Kenya. Principal land uses are subsistence pastoralism, livestock ranching, and wildlifebased tourism. Wild dogs disappeared from the area in the 1980s, but recolonised naturally around 2000, increasing rapidly to densities similar to those observed in protected areas (Woodroffe, 2011a). Local weather patterns are variable and wild dog reproduction is not seasonal (McNutt, Groom, \& Woodroffe, in press). 


\section{Data collection}

We monitored the survival, reproductive status, and behaviour of individual wild dogs (recognisable from their unique pelage patterns, Maddock \& Mills, 1994) during the years 2001-17. Between two and 10 study packs were monitored each year. At least one member of each study pack was fitted with a mortality-sensing radio-collar (Telonics, Mesa, AZ, USA), and from 2011-17 one individual in each pack was fitted with a GPS-collar (GPS-Plus, Vectronic Aerospace GmbH, Berlin, Germany); collar deployment methods are detailed in Woodroffe (2011a). Age at collaring was either known from prior monitoring (65\% overall, 94\% for individuals which dispersed), or estimated from tooth wear, body condition, and social status. We attempted to locate each collared animal at least weekly, either on the ground or from an aircraft. For each visual observation, we recorded pack size (the number of individuals aged $\geq 12$ months), the number of pups (aged $<12$ months), and reproductive status, using photographs to record which individuals (both collared and uncollared) were sighted. We inferred birth dates by identifying when packs started returning daily to the same den location, and considered packs to be denning until they stopped this behaviour ( 89 days later on average, Woodroffe et al., 2017). Mortality signals were investigated immediately, and where possible necropsies were conducted to identify cause of death. Failure to detect any collared animal prompted extensive aerial and ground searches; nevertheless, some collared individuals were lost to monitoring.

\section{Definition of terms}

We defined a pack as a stable social group including members of both sexes. Pack formation occurred when one or more males bonded with one or more females unrelated to the males (McNutt, 1996); these animals were termed pack founders. Within each pack, we identified an alpha male and female based on consistent close association, coordinated scent marking, and reproductive activity. We considered all other individuals subdominant, although we distinguished founder and natal animals, and littermate and non-littermate siblings. In the absence of seasonal reproduction (McNutt et al., in press), we defined a pack-year as the time from leaving one den to leaving the next (mean 332 days, Woodroffe, 2011b); other references to years indicate calendar years. We identified a pack territory as the $100 \%$ Minimum Convex Polygon 
(MCP) encompassing all pack locations within a pack-year. Pack breakup was used to describe the permanent separation of all male pack members from all female members.

We considered a wild dog to have dispersed when it left its pack permanently, either spontaneously or during pack breakup, and was observed in another pack or dispersal group (e.g., Figure 1). Our analyses are restricted to dispersals involving collared individuals. The packs from which dispersers emigrated were termed origin packs, and the packs they subsequently formed or joined were termed destination packs. Individuals were considered resident while they were members of either pack type, and otherwise dispersing. Hence, the dispersal period lasted from the date an individual left its origin pack to the date it was first observed in its destination pack. We distinguished natal dispersers (leaving their natal packs) from secondary dispersers (leaving packs they had founded).

Dispersals contrasted with excursions, when individuals or single-sex groups separated from their packs for $\geq 1$ days before returning. To avoid confusing excursions with failure to detect individuals, or with temporary separation during hunting, we only considered events when the locations of the pack (containing the alpha pair) and the animal(s) on excursion were both known, and confirmed to be $>1 \mathrm{~km}$ apart. We excluded denning periods, when pack members are often separated while some guard pups and others hunt (Malcolm \& Marten, 1982), and locations in the few days before disease-related death, when separation from the pack might reflect morbidity. Excursion group sizes and durations were poorly estimated due to infrequent visual observations.

\section{Behaviour during and after dispersal}

We used GPS-collar data to characterise movement behaviour before, during, and after dispersal for eight wild dogs which dispersed while GPS-collared. GPS-collars were programmed to record locations at $0100 \mathrm{~h}, 0630 \mathrm{~h}, 0700 \mathrm{~h}, 0730 \mathrm{~h}, 0800 \mathrm{~h}, 1300 \mathrm{~h}$, $1800 \mathrm{~h}, 1830 \mathrm{~h}$, and $1930 \mathrm{~h}$, to reflect a crepuscular activity pattern (Woodroffe et al., 2017). We calculated daytime distance travelled as the sum of the distances between successive GPS-collar locations for the period 0630h-1830h, and night-time distance travelled as the equivalent for the period $1830 \mathrm{~h}-0630 \mathrm{~h}$, recognising that these timings would be likely to over-estimate night-time activity and under-estimate daytime activity, since morning hunts often started before $0630 \mathrm{~h}$ and evening hunts often ended 
after 1830h (see Figure 1 in Woodroffe et al., 2017). We excluded days or nights when the GPS failed to record a location at one or more of the scheduled time points.

Each GPS-collar also recorded activity (in two planes, maximum 255 per plane) for every 5-min period, using an integral accelerometer. We summed activity data in the two planes, and then calculated the means across all 5-min intervals for the period between sunrise and sunset times (obtained from

http://aa.usno.navy.mil/data/docs/RS OneYear.php) to give daytime activity, and for the period between sunset and sunrise to give night-time activity.

\section{Dispersal distance}

We calculated three different measures of dispersal distance (Figure 1). Centroid dispersal distance was the distance (in $\mathrm{km}$ ) between the centroids of two minimum convex polygons, each enclosing all locations of the origin and destination packs in, respectively, the 135 days before dispersal and the 135 days after pack formation (monitoring periods lasting 135 days were judged to be long enough to characterise ranging behaviour, while ensuring that the majority of dispersal groups had sufficient data to calculate centroid dispersal distance). Den dispersal distance was the distance (in $\mathrm{km}$ ) between the den site occupied by the origin pack at the start of the last denning period before emigration, and the den site occupied by the destination pack at the start of its first denning period after pack formation. GPS-collar dispersal distance was the distance from each successive GPS-collar location to the next, summed across the entire dispersal period. We used centroid dispersal distance as our primary measure, as it was available for the greatest number of dispersal groups (Table S1), and was closely correlated with den dispersal distance $(r=0.96)$.

\section{Statistical analyses}

All statistical analyses were performed in $R$ (R Core Team, 2015). In testing hypotheses about dispersal behaviour, we made simple comparisons of proportions using Fisher's Exact Test, and comparisons of means using $t$-tests. We expected that dispersal patterns (e.g., dispersal group size) might differ between dispersal types (primary vs. secondary, spontaneous vs. breakup, and male vs. female) but, rather than analysing these types separately, we fitted statistical models to the complete dataset, and assessed the impact of including variables describing these dispersal types. In each 
model, we accounted for repeated measures from the same individual, dispersal group, or pack by including the appropriate identity variable, as a random effect if there were $\geq 10$ individual, groups or packs and otherwise a categorical fixed effect.

We tested the hypothesis that males and females dispersed at different ages by fitting a Generalised Linear Mixed Model (GLMM) with normally-distributed errors, with individual age at dispersal (in years, expressed as decimals, e.g. 1.86 years) as the outcome variable, dispersal group identity as a random effect, and dispersal number (primary vs. secondary) as a fixed effect. We then explored the effects of adding variables describing sex, and dispersal cause (spontaneous vs. breakup).

We tested the hypothesis that males and females dispersed in groups of different size by fitting a Generalised Linear Mixed Model (GLMM) with Poisson errors, with dispersal group size as the outcome variable, dispersal group identity as a random effect, and dispersal number (primary vs. secondary) as a fixed effect. Because not all dispersal group members were littermates, we included age of the youngest member (ln-transformed as is appropriate for a Poisson regression) as a covariate. We then explored the effects of adding variables describing sex, and dispersal cause (spontaneous vs. breakup).

We likewise used a GLMM with normally-distributed errors to test the hypothesis that dispersal extended inter-birth intervals, comparing the time (in days) between successive births within established packs with the time (in days) between the last birth in dispersers' origin packs and the first birth in their destination packs, distinguishing spontaneous and breakup dispersals. This model included pack identity as a random effect.

We tested the hypotheses that GPS-collared wild dogs increased their activity and distance travelled during dispersal. To perform these hypothesis tests, we first constructed base models of distance travelled and activity, based on Rabaiotti \& Woodroffe (2019), for both daytime and night-time. Base models were generalised linear models with normal error distribution. Each model included individual identity as a categorical variable; with only eight individuals there were too few groups to meet the assumptions of models with random effects. Following Rabaiotti \& Woodroffe (2019), base models included, as explanatory variables, daily maximum temperature (measured at Mpala Research Centre within the study area, Caylor, Gitonga, \& Martins, 2017) and moonlight (expressed as full-moon-equivalent hours between sunset and 
sunrise, calculated using data from

http://aa.usno.navy.mil/data/docs/MoonFraction.php and

http://aa.usno.navy.mil/data/docs/RS OneYear.php), as these variables have

previously been found to influence wild dog movement behaviour (Cozzi et al., 2012;

Rabaiotti \& Woodroffe, 2019; Woodroffe et al., 2017). We then explored the effects of dispersal by adding a categorical variable describing whether the individual wild dog was dispersing or resident. We excluded data collected during the denning period from these analyses, since denning alters ranging and activity patterns (Rabaiotti \& Woodroffe, 2019; Woodroffe et al., 2017).

We likewise tested the hypothesis that the movement and activity patterns associated with dispersal persisted following pack formation. We used the same base models described above, but instead fitted them to data collected after recent dispersers were first sighted with new pack members. We then added a variable describing the time (in days) since formation of the new pack, again excluding data from denning periods.

\section{Results}

\section{Emigration}

Most African wild dogs dispersed from their natal packs, if they survived long enough to do so. Of 74 animals radio-collared in their natal packs, 51 dispersed, 19 died in their natal packs, and three were lost to monitoring after collar failure; only one acquired alpha status without emigrating (Figure 2).

In total, we recorded 63 individuals of known origin making 69 dispersals before, during, or after they were radio-collared (Table 1, Table S2). These individuals were members of 44 dispersal groups, all single-sex. Of these 44 dispersal groups, 38 left their packs spontaneously, while six dispersed during pack breakup (Table 1). Thirty-eight of the 44 dispersal groups comprised animals leaving their natal packs, five groups comprised secondary dispersers leaving packs they had founded, and one group included one natal and one secondary disperser (Table 1). All six groups including secondary dispersers were female: of 63 dispersing individuals, six of 34 females dispersed twice, compared with none of 29 males (Fisher exact $\mathrm{p}=0.027$ ). 
Dispersal groups departed in all months of the year, with little evidence of seasonality (Figure S1A). There was likewise no evidence that dispersers left at a consistent time after birth of their origin pack's most recent litter (Figure S1B).

In line with expectations, mean dispersal age (in years) was higher for secondary dispersers than natal dispersers (Table 1; GLMM with normally distributed errors, including dispersal group identity as a random variable; effect of being a secondary disperser 1.46, SE 0.33, p<0.001; Table S3). After accounting for this covariate, there was no association between dispersal age and sex or dispersal cause (Table S3). In eight litters with both male and female littermates collared before dispersal, males departed before females in four litters, and females before males in four litters.

Dispersal group size was greater for groups containing younger members (GLM with Poisson errors, effect of $\ln$ (age [in years] of youngest member) -0.867, SE 0.304, $\mathrm{p}=0.004$; Table S4). After adjusting for this effect of age, dispersal group size was not significantly associated with sex, dispersal number, or dispersal cause (Table S4).

Among 25 dispersal groups numbering at least two individuals, in which all individuals' birth dates were known, 24 were comprised entirely of siblings, of which eight groups included siblings from more than one litter. These eight multi-litter dispersal groups were not larger (mean 4.57 animals, SD 2.51) than the 16 single-litter groups (mean 3.56, SD 0.96) and adding a variable describing these two types of sibling group did not improve the fit of the group size model described above (effect of being a multi-litter group 0.253, SE 0.221, p=0.253).

\section{Fates of emigrants}

Of the 69 dispersal events listed in Table 1, 54 involved individuals collared at the time of dispersal (Tables S2). Of these, 31 formed new packs, two joined an existing pack, nine died, and 12 were lost to monitoring. The nine deaths occurred among 49 collared individuals monitored for all or part of their dispersal period, over a combined total of 1,535 days, giving mortality rate which equivalent to $88.3 \%$ p.a. (calculated as [1-(1-[9/1535] $)^{365] ;}$; exact binomial 95\% CI 62.7-98.3\%; note that dispersers spent substantially less than a year dispersing, so the mortality rate per dispersal was much lower than 88.3\%). Six of these nine deaths were attributable to known causes: five were killed by people (shot, snared, or hit by vehicles) and one was killed by a predator. This proportion of human-caused deaths $(5 / 6,83.3 \%)$ was significantly higher than 
that for collared animals in resident packs $(11 / 49,22.4 \%$, Fisher exact $\mathrm{p}=0.006)$, while the proportion of predator-caused deaths $(1 / 6,16.7 \%)$ was similar to that in resident packs $(11 / 49,22.4 \%)$. Two groups split up during dispersal; both appeared to have been separated by the same game fence.

Pack formation entailed the establishment of new alphas. Of 46 alpha individuals of known origin, 45 (23 females and 22 males) acquired alpha status after dispersal. The one exception was a female who inherited alpha status from her mother following a unique incident of male immigration to her natal pack. Of the 45 individuals which became alphas after dispersal, 20 females and 20 males became alphas immediately after forming new packs, three (one female and two males) inherited alpha status after a co-founder died, and two females joined existing packs within which the founding alpha females had died. Eventual alpha status was known for individuals in five of nine multi-litter dispersal groups ( 3 female, 2 male). In none of these five groups did the oldest member become alpha, although in three cases ( 2 female, 1 male) this individual died before pack formation.

On average, 167.9 days (SD 95.9 days) elapsed between the first sighting of a newly-formed pack and the birth of its first litter. A GLMM with normally-distributed errors indicated that the interval between the last birth in the origin pack before spontaneous dispersal and the first birth in the destination pack (mean 379.5 days, SD 111.2 days) was longer than the interval between successive births within resident packs (mean 325 days, SD 46.3 days), but shorter than the equivalent interval for breakup dispersal (mean 623.5 days, SD 9.2 days; Table S5).

\section{Dispersal time and distance}

For successful dispersal groups (those observed to form or join packs), dispersal time averaged 19.4 days (range 3-68 days). This figure probably under-estimates true dispersal time; three of nine collared individuals that died during dispersal (after 51 days on average, range 37-71 days) had uncollared group-mates that were subsequently sighted in new packs, suggesting more prolonged dispersal.

Centroid dispersal distance averaged $37 \mathrm{~km}$ (range $2-87 \mathrm{~km}$ ), although this measure under-estimated by an order of magnitude the actual distances travelled by dispersers (mean 487km, range 43-1,689km; Figure 1, Table S1). There was no significant difference in centroid dispersal distance between male (mean $41.0 \mathrm{~km}$, SD 
$27.9 \mathrm{~km}$ ) and female dispersal groups (mean 33.5km, SD 20.5km; $\mathrm{t}=0.81, \mathrm{p}=0.42$ ). Repeated long-distance dispersals from origin packs led to the potential for gene flow over thousands of $\mathrm{km}^{2}$ (Figure 3).

\section{Movement behaviour during and after dispersal}

Individual wild dogs were more active and travelled further, both day and night, when dispersing than when resident (Table 2; Table S6). Significant effects of the interactions between dispersal and moonlight, and dispersal and temperature indicated that, when dispersing, wild dogs responded to more moonlight and higher daytime temperatures by increasing their night-time activity and distances travelled to a greater extent than when resident (Figure 4). This altered behaviour was observed among animals which dispersed long distances (e.g. Figure 1A), as well as those which established new territories overlapping their origin pack territories (e.g. Figure 1B); replacing the two-level dispersal variable (resident or dispersing) with a three-level variable (resident, dispersing short distance, or dispersing long distance) revealed no significant difference in behaviour between dispersal distance types (Table S7).

Newly-formed packs continued to range relatively widely after formation. Both daytime and night-time activity and daily distance travelled declined over time after pack formation (Table 3; Table S8), with ranging behaviour settling down only after 3-4 months (Figure 5). There was no detectable difference in this behaviour between longand short-distance dispersers (Table S7).

\section{Excursions}

We recorded 16 temporary excursions, 14 involving female individuals or groups, and two involving single males. All of the females, and one of the males, went on excursions from their natal packs; the second male was a subdominant pack founder. Limited sightings indicated that excursion groups numbered 1-6 individuals. Of 46 individuals that were collared $>30$ days before dispersing from their natal packs, 11 of 24 females (46\%) were observed making pre-dispersal excursions, compared with none of 22 males (Fisher exact $\mathrm{p}<0.001$ ). Some animals that made excursions together subsequently dispersed with different individuals. Animals on excursions were recorded on average $10.0 \mathrm{~km}$ from their packs (range $2.0-28.4 \mathrm{~km}$ ), with $50 \%$ of excursion groups detected outside their pack territories. 


\section{Discussion}

Our results confirm the central role that dispersal plays in African wild dog social organisation and demography. Although dispersal carried a mortality cost, most individuals dispersed from their natal packs and dispersal was the principal route to reproduction; $98 \%$ of alphas acquired their status through dispersal. At the population level, dispersal was the only mechanism whereby new packs were formed. Most dispersers formed new packs, the only exceptions being two instances of females joining existing packs to take up vacant alpha positions. Long-distance dispersals (e.g., Figure 3) facilitated recolonisation of the study site following local extirpation in the 1980s (Woodroffe, 2011a). For these multiple reasons, individuals' dispersal decisions had pervasive impacts on demography.

Although our sample of GPS-collared dispersers was small, it suggested that the behavioural state of individuals differed between periods of dispersal and residence. When dispersing, collared individuals travelled further, not only by day but also by night, exploiting favourable conditions of light and temperature to move further. This behaviour is consistent with animals moving as rapidly as possible as they searched for mates and territories. This altered behaviour was observed among animals which established new territories overlapping their origin pack territories (e.g. Figure 1B), as well as those which dispersed further (e.g. Figure 1A), and justified our decision to classify both as dispersal. Increased nocturnal activity might have been expected to increase dispersing wild dogs' susceptibility to predation, relative to resident packs, but there was no evidence that predation mortality increased in this way.

Importantly, wild dogs did not travel directly from their origin to their destination territories, instead following extensive paths an order of magnitude longer than the straight-line distance covered. These meandering paths may reflect dispersers' need to find mates, as well as territories in suitable habitat, and contrast with the leastcost paths often hypothesised in analyses of landscape connectivity. O'Neill et al. (in review) and Jackson et al. (2016) both found that wild dogs were less selective in their habitat selection when dispersing than when resident. Hence, even dispersal groups with origin and destination territories located in contiguous wildlife-friendly habitat may spend part of their dispersal period in more human-impacted areas, where they are exposed to a variety of threats. This willingness to traverse human-impacted lands 
probably explains the preponderance of human-caused mortality that we described among dispersers, which may in turn help to explain high dispersal mortality (equivalent to $88.3 \%$ p.a., 95\% CI 62.7-98.3\%, compared with an average of $29.0 \%$ p.a., 95\% CI 21.1-38.1\% among radiocollared adults and yearlings Woodroffe, 2011a). This high mortality of dispersers is likely to reduce effective connectivity between patches of suitable habitat. Moreover, as high costs of dispersal are thought to favour delayed dispersal and hence cooperative breeding (Emlen, 1982), it is possible that, as well as impacting demography, human-caused mortality might influence behavioural strategies among wild dogs.

We found that the expanded ranging behaviour associated with dispersal declined only gradually after pack formation (Figure 5, Table 3). This pattern suggests a difference between social and spatial dispersal: wild dogs appeared to find mates before they established territories. We defined the dispersal period based on social criteria (i.e., from leaving the origin pack to being sighted in the destination pack), but it is possible that a definition based on spatial criteria (such as Net Squared Displacement, Börger \& Fryxell, 2012) might have identified longer dispersal periods. Habitat selection of newly-formed packs has not been explored, but it is possible that they may be exposed to risks of elevated mortality similar to those experienced by dispersers.

Our results suggest that females experienced more intense competition for reproduction than did males. Unlike males, females undertook secondary dispersals, probably reflecting their low probability (relative to males) of reproducing following natal dispersal if they fail to attain alpha status (Creel et al., 1997). Pre-dispersal excursions were likewise observed primarily among females. It is not clear whether these excursions represented prospecting for future dispersal opportunities, or failed dispersal attempts; in either case, they suggest greater selectivity in dispersal decisions among females than males.

Our findings help to resolve dissimilarities between previous studies of wild dog dispersal. While McNutt (1996) found that almost all individuals left their natal packs to form new packs, seldom immigrating into existing packs, Frame et al. (1979) described male lineages persisting over multiple generations and females immigrating to join these long-lived packs. Our findings are similar to those of McNutt (1996), but we also observed two breakup dispersals resembling the pattern described by Frame et al. (1979), with male survivors establishing territories overlapping their natal ranges (e.g., 
Figure 1B). Creel and Creel (2002) mention having observed a similar pattern. We classified these events as dispersals because the males showed altered movement behaviour, increasing daytime and night-time travel distance as they made repeated forays outside their normal home ranges (Figure 1B), before joining with unrelated females to form new packs. (According to our definitions, these were new packs because they contained neither the original founders [which had all died] nor their descendants of both sexes [as the females had all dispersed]). Without GPS-collars (unavailable to Frame et al. (1979) or Creel and Creel (2002)), we would have been unaware of this altered movement behaviour, and might have assumed that males had remained in their home ranges and females immigrated, as described by Frame et al. (1979). Hence, there may be less marked geographic variation in dispersal behaviour (and hence population dynamics) than inferred by previous studies.

The central role of dispersal in wild dog population dynamics means that demographic models need to represent this process accurately. In practice, this means tracking individuals' sex, pack membership, and status as founders or natal individuals. Existing demographic models have either ignored social structure (Cross \& Beissinger, 2001; Ginsberg \& Woodroffe, 1997) or represented it using dispersal rules which are not supported by empirical evidence from this or any other study population, such as assuming frequent inheritance of alpha status within the natal pack (which we observed in only one of 46 alphas), and joining of existing packs by dispersers (which we observed in only two of 42 known-fate dispersers, Courchamp et al., 2000; Gusset et al., 2009; Prager et al., 2011; Vial et al., 2006; Vucetich \& Creel, 1999). Such inaccuracies in model structure are likely to generate inaccurate model outcomes; for example, assuming that alphas are typically replaced by existing pack members would ignore the marked increases in mortality and interbirth interval which we found to be associated with pack breakup and subsequent dispersal, potentially over-estimating population growth. Given the importance of demographic modelling for planning the conservation of this endangered species, new population models are needed which represent dispersal processes more accurately.

\section{Acknowledgements}

We thank the landowners and communities within our study site for hosting our research, Kenya Wildlife Service for collaboration and the Kenya National Council for 
Science and Technology for research permission. We also thank funders and research assistants too numerous to list individually.

\section{Data availability}

Data associated with this manuscript will be made available on Dryad on acceptance.

\section{References}

Angulo, E., Rasmussen, G. S. A., Macdonald, D. W., \& Courchamp, F. (2013). Do social groups prevent Allee effect related extinctions?: The case of wild dogs. Frontiers in Zoology, 10, 13. doi:10.1186/1742-9994-10-11

Bateman, A. W., Coulson, T., \& Clutton-Brock, T. H. (2011). What do simple models reveal about the population dynamics of a cooperatively breeding species? Oikos, 120(5), 787-794. doi:10.1111/j.1600-0706.2010.18952.x

Bateman, A. W., Ozgul, A., Coulson, T., \& Clutton-Brock, T. H. (2012). Density dependence in group dynamics of a highly social mongoose, Suricata suricatta. Journal of Animal Ecology, 81(3), 628-639. doi:10.1111/j.1365-2656.2011.01934.x

Bateman, A. W., Ozgul, A., Krkosek, M., \& Clutton-Brock, T. H. (2018). Matrix models of hierarchical demography: linking group- and population-level dynamics in cooperative breeders. American Naturalist, 192(2), 188-203. doi:10.1086/698217

Börger, L., \& Fryxell, J. (2012). Quantifying individual differences in dispersal using net squared displacement. Oxford: Oxford University Press.

Caylor, K. K., Gitonga, J., \& Martins, D. J. (2017). Mpala Research Centre Meteorological and Hydrological Dataset

Courchamp, F., Clutton-Brock, T., \& Grenfell, B. (2000). Multipack dynamics and the Allee effect in the African wild dog, Lycaon pictus. Animal Conservation, 3, 277285. doi:10.1111/j.1469-1795.2000.tb00113.x

Courchamp, F., \& Macdonald, D. W. (2001). Crucial importance of pack size in the African wild dog Lycaon pictus. Animal Conservation, 4, 169-174.

Cozzi, G., Broekhuis, F., McNutt, J. W., Turnbull, L. A., Macdonald, D. W., \& Schmid, B. (2012). Fear of the dark or dinner by moonlight? Reduced temporal partitioning among Africa's large carnivores. Ecology, 93(12), 2590-2599. 
Craft, M. E., Hawthorne, P. L., Packer, C., \& Dobson, A. P. (2008). Dynamics of a multihost pathogen in a carnivore community. Journal of Animal Ecology, 77(6), 12571264. doi:10.1111/j.1365-2656.2008.01410.x

Creel, S., \& Creel, N. M. (2002). The African wild dog: behavior, ecology and conservation. Princeton: Princeton University Press.

Creel, S., \& Creel, N. M. (2015). Opposing effects of group size on reproduction and survival in African wild dogs. Behavioral Ecology, 26(5), 1414-1422. doi:10.1093/beheco/arv100

Creel, S., Creel, N. M., Mills, M. G. L., \& Monfort, S. L. (1997). Rank and reproduction in cooperatively breeding African wild dogs: Behavioral and endocrine correlates. Behavioural Ecology, 8, 298-306.

Creel, S., Mills, M. G. L., \& McNutt, J. W. (2004). Demography and population dynamics of African wild dogs in three critical populations. In D. W. Macdonald \& C. SilleroZubiri (Eds.), The biology \& conservation of wild canids (pp. 337-350). Oxford: Oxford University Press.

Cross, P. C., \& Beissinger, S. R. (2001). Using logistic regression to analyse the sensitivity of PVA models: a comparison of methods based on African wild dog models. Conservation Biology, 15, 1335-1346.

Davies-Mostert, H. T., Kamler, J. F., Mills, M. G. L., Jackson, C. R., Rasmussen, G. S. A., Groom, R. J., \& Macdonald, D. W. (2012). Long-distance transboundary dispersal of African wild dogs among protected areas in southern Africa. African Journal of Ecology, 50(4), 500-506. doi:10.1111/j.1365-2028.2012.01335.x

Ebensperger, L. A., \& Hayes, L. D. (2008). On the dynamics of rodent social groups. Behavioural Processes, 79(2), 85-92. doi:10.1016/j.beproc.2008.05.006

Emlen, S. T. (1982). The evolution of helping. 1. An ecological constraints model. American Naturalist, 119(1), 29-39. doi:10.1086/283888

Fattebert, J., Dickerson, T., Balme, G., Slotow, R., \& Hunter, L. (2013). Long-distance natal dispersal in leopard reveals potential for a three-country metapopulation. South African Journal of Wildlife Research, 43(1), 61-67. doi:10.3957/056.043.0108

Frame, L. H., Malcolm, J. R., Frame, G. W., \& van Lawick, H. (1979). Social organization of African wild dogs (Lycaon pictus) on the Serengeti Plains. Zeitschrift für Tierpsychologie, 50, 225-249. 
Ginsberg, J. R., \& Woodroffe, R. (1997). Extinction risks faced by remaining wild dog populations. In R. Woodroffe, J. R. Ginsberg, \& D. W. Macdonald (Eds.), The African wild dog: Status survey and conservation action plan (pp. 75-87). Gland: IUCN.

Gusset, M., Jakoby, O., Muller, M. S., Somers, M. J., Slotow, R., \& Grimm, V. (2009). Dogs on the catwalk: Modelling re-introduction and translocation of endangered wild dogs in South Africa. Biological Conservation, 142(11), 2774-2781. doi:10.1016/j.biocon.2009.07.007

Jackson, C. R., Marnewick, K., Lindsey, P. A., Roskaft, E., \& Robertson, M. P. (2016). Evaluating habitat connectivity methodologies: a case study with endangered African wild dogs in South Africa. Landscape Ecology, 31(7), 1433-1447. doi:10.1007/s10980-016-0342-5

Lerch, B. A., Nolting, B. C., \& Abbott, K. C. (2018). Why are demographic Allee effects so rarely seen in social animals? Journal of Animal Ecology, 87(6), 1547-1559. doi:10.1111/1365-2656.12889

Macedo, R. H. F., Cariello, M. O., Graves, J., \& Schwabl, H. (2004). Reproductive partitioning in communally breeding guira cuckoos, Guira guira. Behavioral Ecology and Sociobiology, 55(3), 213-222. doi:10.1007/s00265-003-0697-x

Maddock, A. H., \& Mills, M. G. L. (1994). Population characteristics of the African wild dogs Lycaon pictus in the eastern Transvaal lowveld, South Africa, as revealed through photographic records. Biological Conservation, 67, 57-62.

Malcolm, J. R., \& Marten, K. (1982). Natural selection and the communal rearing of pups in African wild dogs (Lycaon pictus). Behavioural Ecology and Sociobiology, 10, 113.

McNutt, J. W. (1996). Sex-biased dispersal in African wild dogs, Lycaon pictus. Animal Behaviour, 52, 1067-1077.

McNutt, J. W., Groom, R., \& Woodroffe, R. (in press). High ambient temperatures explain seasonal reproduction in a tropical mammal. Journal of Zoology.

Nascimento, A. T. A., Nali, C., \& da Fonseca, G. A. B. (2014). Dispersal, group formation and kinship in the black-faced lion tamarin (Leontopithecus caissara). Folia Primatologica, 85(4), 216-227. doi:10.1159/000363058

Newby, J. R., Mills, L. S., Ruth, T. K., Pletscher, D. H., Mitchell, M. S., Quigley, H. B., . . DeSimone, R. (2013). Human-caused mortality influences spatial population 
dynamics: Pumas in landscapes with varying mortality risks. Biological Conservation, 159, 230-239. doi:10.1016/j.biocon.2012.10.018

O'Neill, H. M. K., Durant, S., \& Woodroffe, R. (in review). Habitat selection differs across life stages and orders of selection in a wide-ranging carnivore.

Pilot, M., Dahlheim, M. E., \& Hoelzel, A. R. (2010). Social cohesion among kin, gene flow without dispersal and the evolution of population genetic structure in the killer whale (Orcinus orca). Journal of Evolutionary Biology, 23(1), 20-31. doi:10.1111/j.1420-9101.2009.01887.x

Prager, K. C., Mazet, J. K., Dubovi, E. J., Frank, L. G., Munson, L., Rupprecht, C. E., . . . Woodroffe, R. (2013). Rabies and canine distemper virus in wild and domestic carnivores in northern Kenya: Are domestic dogs the reservoir? Ecohealth, 9, 483.

Prager, K. C., Woodroffe, R., Cameron, A., \& Haydon, D. T. (2011). Vaccination strategies to conserve the endangered African wild dog (Lycaon pictus). Biological Conservation, 144, 1940-1948.

Proctor, M. F., Paetkau, D., McLellan, B. N., Stenhouse, G. B., Kendall, K. C., Mace, R. D., ... Strobeck, C. (2012). Population fragmentation and inter-ecosystem movements of grizzly bears in western Canada and the northern United States. Wildlife Monographs(180), 1-46. doi:10.1002/wmon.6

Pusey, A. E. (1987). Sex biased dispersal and inbreeding avoidance in birds and mammals. Trends in Ecology \& Evolution, 2, 295-299.

R Core Team. (2015). R: A language and environment for statistical computing. Vienna, Austria: R Foundation for Statistical Computing http://www.R-project.org.

Rabaiotti, D., \& Woodroffe, R. (2019). Coping with climate change: limited behavioural responses to hot weather in a tropical carnivore. Oecologia, 189, 587-599.

Rasmussen, G. S. A., Gusset, M., Courchamp, F., \& Macdonald, D. W. (2008). Achilles' heel of sociality revealed by energetic poverty trap in cursorial hunters. American Naturalist, 172, 508-518.

Riley, S. P. D., Serieys, L. E. K., Pollinger, J. P., Sikich, J. A., Dalbeck, L., Wayne, R. K., \& Ernest, H. B. (2014). Individual behaviours dominate the dynamics of an urban mountain lion population isolated by roads. Current Biology, 24(17), 1989-1994. doi:10.1016/j.cub.2014.07.029 
Robertson, B. C., Chilvers, B. L., Duignan, P. J., Wilkinson, I. S., \& Gemmell, N. J. (2006). Dispersal of breeding, adult male Phocarctos hookeri: Implications for disease transmission, population management and species recovery. Biological Conservation, 127(2), 227-236. doi:10.1016/j.biocon.2005.08.011

Stokes, E. J., Parnell, R. J., \& Olejniczak, C. (2003). Female dispersal and reproductive success in wild western lowland gorillas (Gorilla gorilla gorilla). Behavioral Ecology and Sociobiology, 54(4), 329-339. doi:10.1007/s00265-003-0630-3

Sutherland, C., Elston, D. A., \& Lambin, X. (2012). Multi-scale processes in metapopulations: contributions of stage structure, rescue effect, and correlated extinctions. Ecology, 93(11), 2465-2473. doi:10.1890/12-0172.1

Vial, F., Cleaveland, S., Rasmussen, G. S. A., \& Haydon, D. T. (2006). Development of vaccination strategies for the management of rabies in African wild dogs. Biological Conservation, 131, 180-192.

Vucetich, J. A., \& Creel, S. (1999). Ecological interactions, social organisation, and extinction risk in African wild dogs. Conservation Biology, 13, 1172-1182.

Woodroffe, R. (2011a). Demography of a recovering African wild dog (Lycaon pictus) population. Journal of Mammalogy, 92, 305-315.

Woodroffe, R. (2011b). Ranging behaviour of African wild dog packs in a humandominated landscape. Journal of Zoology, 283, 88-97.

Woodroffe, R., Chapman, K., \& Lemusana, E. (2009). Solitary breeding in an African wild $\operatorname{dog}$ (Lycaon pictus). African Journal of Ecology, 47(4), 790-791. doi:10.1111/j.1365-2028.2008.00979.x

Woodroffe, R., Groom, R., \& McNutt, J. W. (2017). Hot dogs: high ambient temperatures influence reproductive success in a tropical mammal. Journal of Animal Ecology, $86,1329-1338$.

Woodroffe, R., O’Neill, H. M. K., \& Rabaiotti, D. (in press). Within- and between-group dynamics in an obligate cooperative breeder. Journal of Animal Ecology.

Woodroffe, R., \& Sillero-Zubiri, C. (2013). African wild dog Red List Assessment. Gland: IUCN.

Zeigler, S. L., \& Walters, J. R. (2014). Population models for social species: lessons learned from models of Red-cockaded Woodpeckers (Picoides borealis). Ecological Applications, 24(8), 2144-2154. doi:10.1890/13-1275.1 


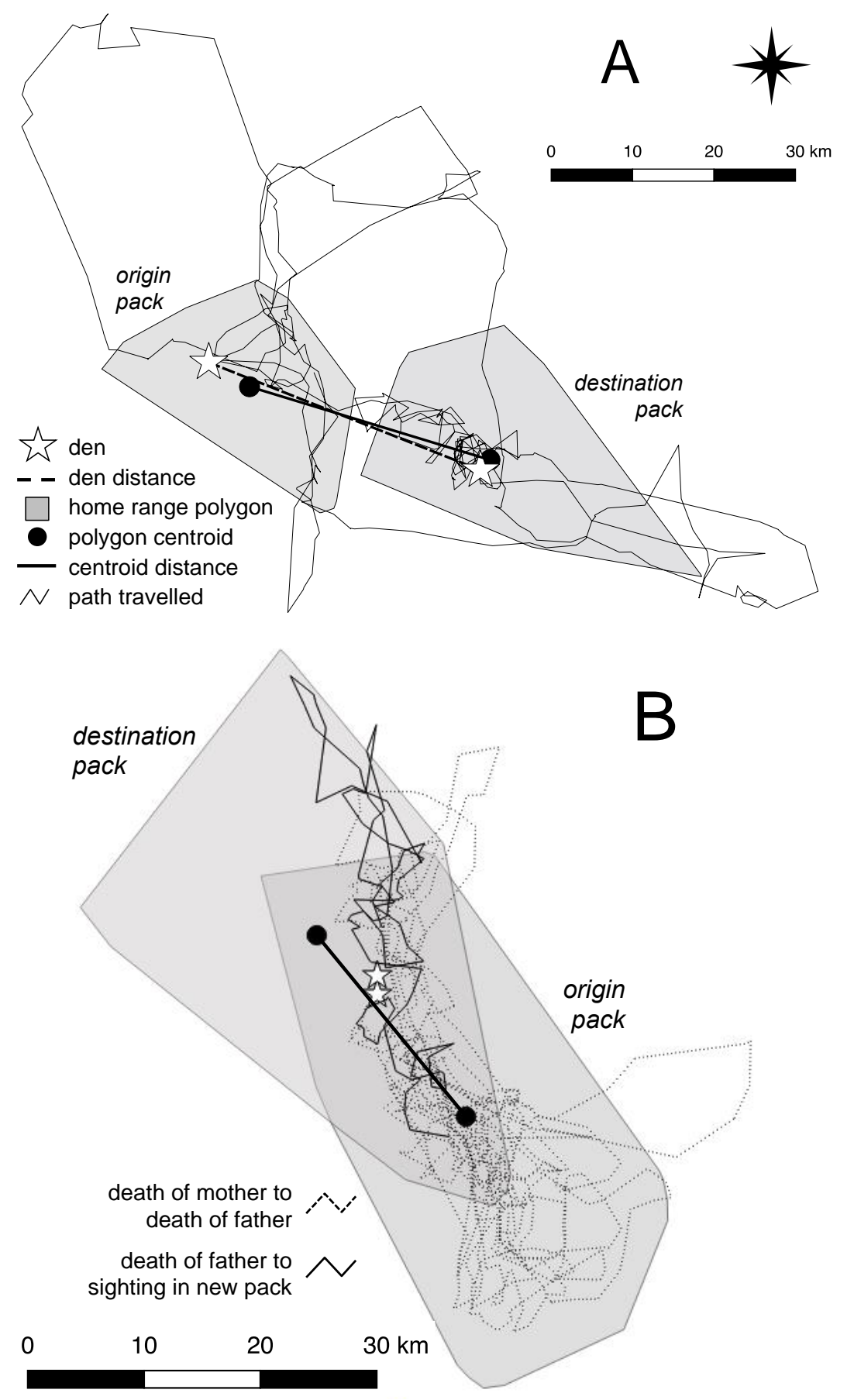

Figure 1 Examples of African wild dog dispersal. Maps show home range polygons (100\% MCP) for origin and destination packs, and three measures of dispersal distance, for two GPS-collared wild dogs. WDF120 (A) and her sisters showed a typical spontaneous dispersal, ranging widely before establishing a new territory distinct from their natal territory. WDM119 (B) and his brothers underwent a breakup dispersal after their parents died four months apart, making several forays outside their natal range before establishing a new territory overlapping their natal range. 


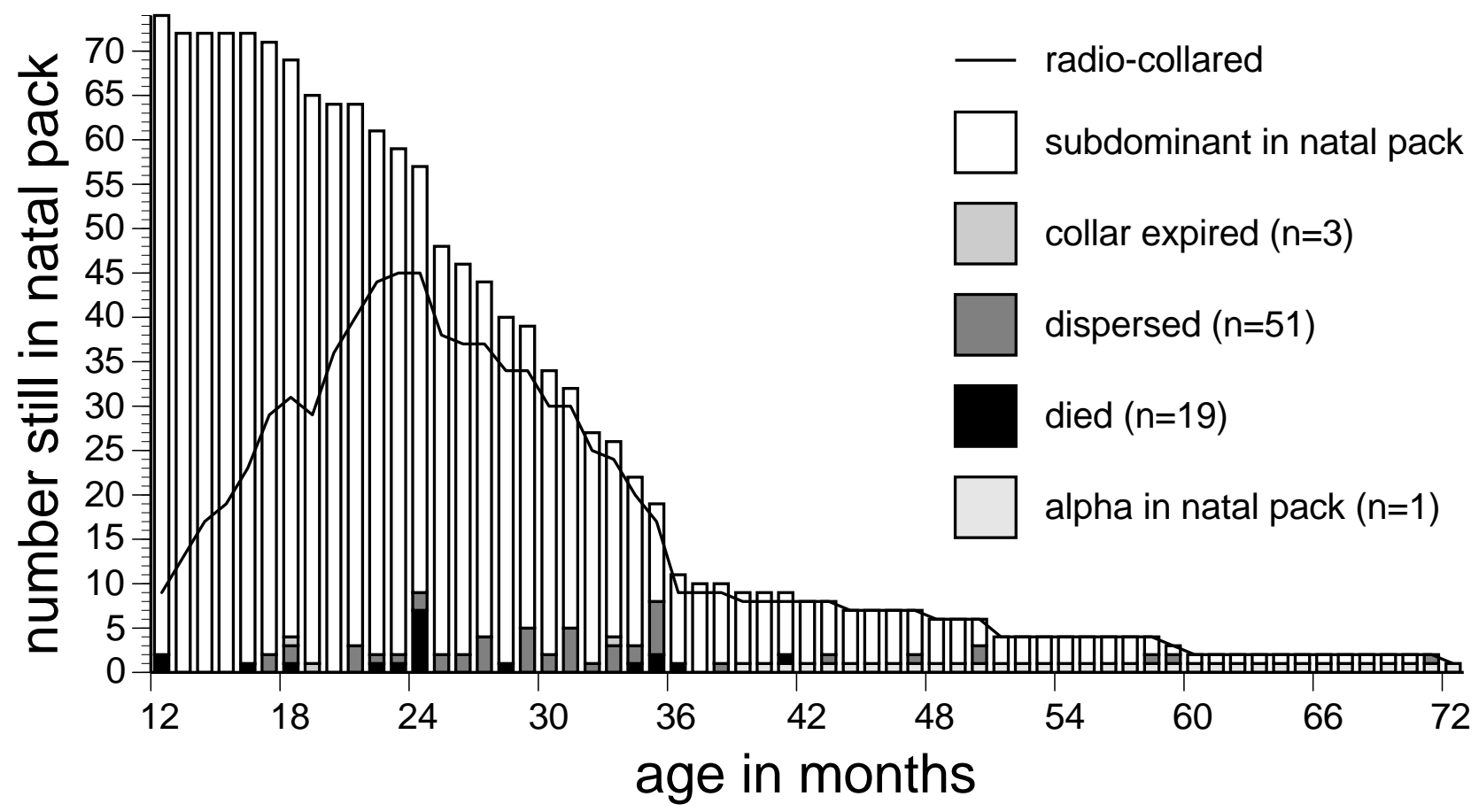

Figure 2 Fates of 74 African wild dogs radio-collared in their natal packs. All started as subdominants; only one acquired alpha status in its natal pack. Most animals dispersed from their natal packs at 18-36 months of age. The solid line indicates the number of animals being monitored by radio-collar at each age (though all were individually identified at $\leq 12$ months). Death and dispersal can only be reliably distinguished in collared animals so may be under-estimated at younger ages when fewer had been collared. 


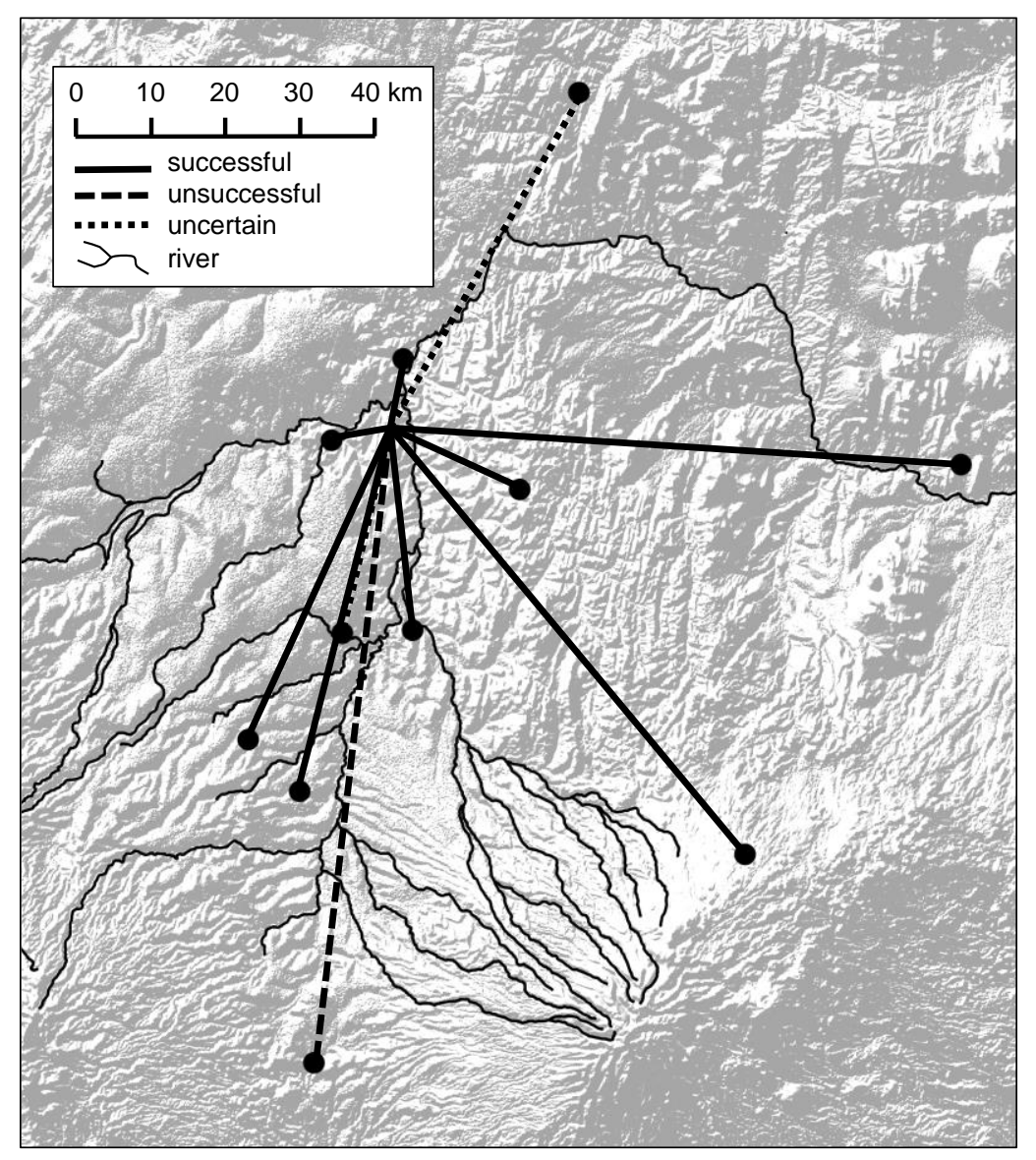

Figure 3 Spatial scale of dispersal in African wild dogs. The map shows, as an example, the fates of 11 dispersal groups originating from the same natal pack; all were offspring of the same alpha pair. Dispersals are classified as successful (formed a new pack), unsuccessful (died), or uncertain (lost to monitoring). Locations are polygon centroids for successful dispersers, and last recorded locations for unsuccessful and uncertain dispersals. 

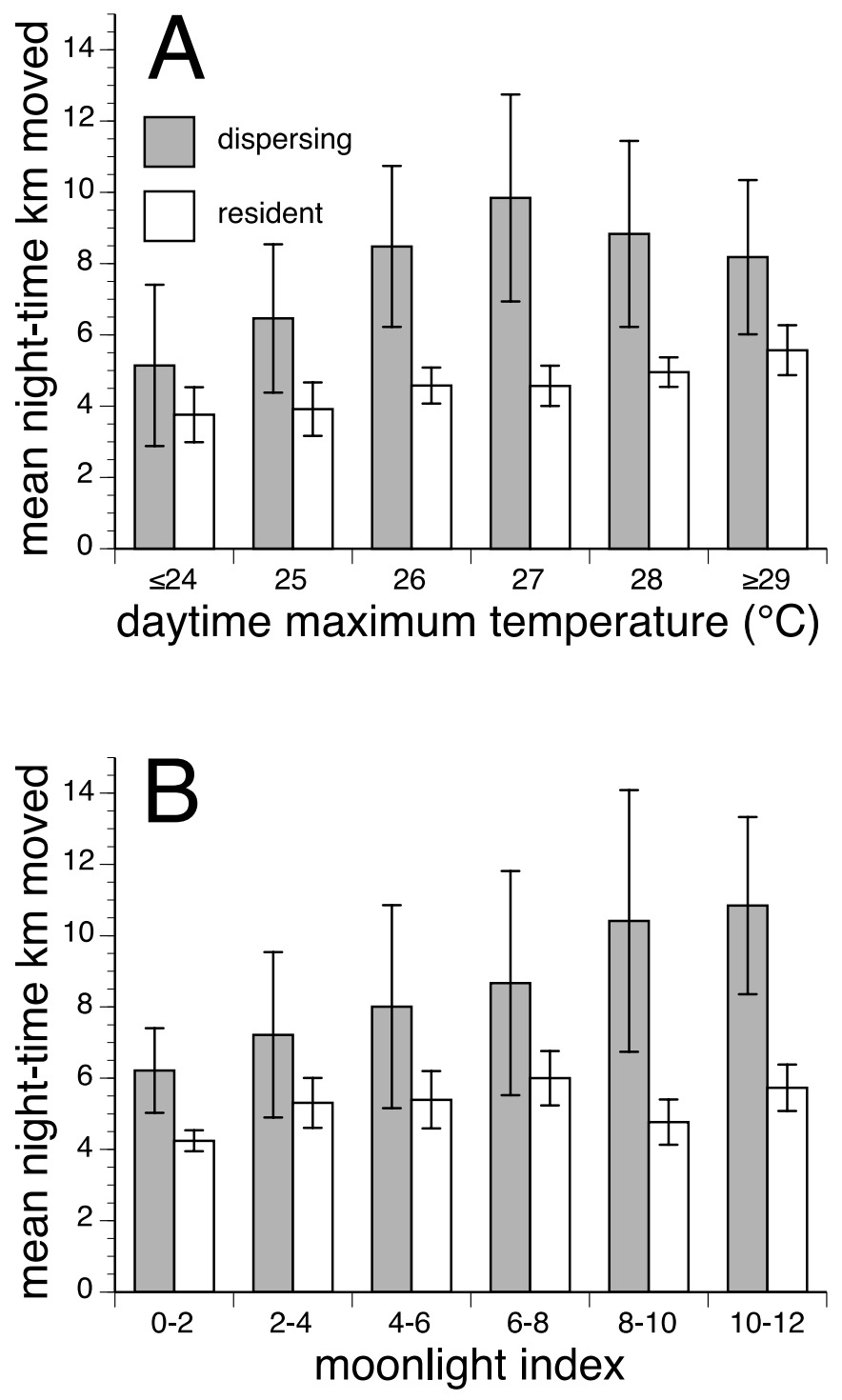

Figure 4 Distances moved during night-time by eight GPS-collared wild dogs tracked both while dispersing and while resident, showing responses to (A) maximum temperature during the previous daylight period, and (B) availability of moonlight (in full moon-hours equivalent). Temperature and moonlight are categorised for illustrative purposes; statistical analyses on continuous data are shown in Table 2. Error bars indicate $95 \%$ confidence intervals. 


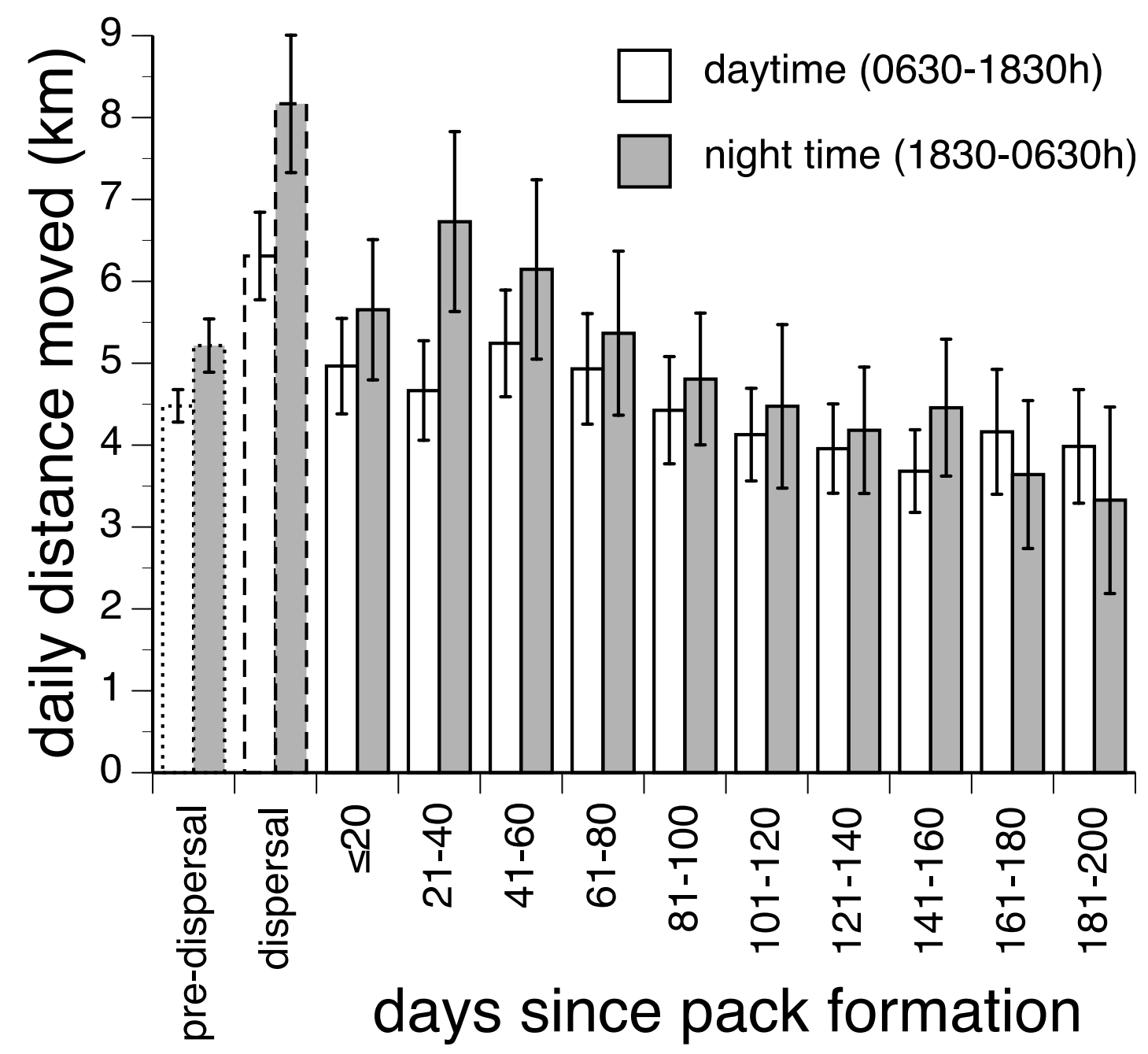

Figure 5 Daily distances travelled by seven GPS-collared African wild dogs before, during, and after dispersal. Note that time categories are shown here for illustrative purposes; statistical analyses presented in Table 3 were conducted on continuous data and did not include periods before (dotted bars) and during (dashed bars) dispersal. Error bars indicate 95\% confidence intervals. 
Table 1 Characteristics of dispersals involving African wild dogs individually identified before dispersal, and fitted with radio- or GPS-collars before, during, or after dispersal. The 69 dispersal events involved 63 individuals (detailed in Table S2).

\begin{tabular}{|c|c|c|c|c|c|c|c|c|}
\hline & \multicolumn{2}{|c|}{$\begin{array}{c}\text { individual } \\
\text { dispersal } \\
\text { events }\end{array}$} & \multicolumn{2}{|c|}{$\begin{array}{l}\text { dispersal } \\
\text { groups }\end{array}$} & \multicolumn{2}{|c|}{$\begin{array}{l}\text { group size } \\
\text { mean } \pm S D\end{array}$} & \multicolumn{2}{|c|}{$\begin{array}{l}\text { age (years) } \\
\text { mean } \pm S D\end{array}$} \\
\hline & $F$ & $M$ & $F$ & $M$ & $F$ & $M$ & $F$ & $M$ \\
\hline \multicolumn{9}{|c|}{ Natal dispersal } \\
\hline spontaneous & 28 & 24 & 19 & 15 & $2.9 \pm 1.3$ & $3.7 \pm 2.1$ & $2.5 \pm 0.8$ & $2.4 \pm 0.8$ \\
\hline breakup & 4 & 5 & 2 & 3 & $5.5 \pm 2.1$ & $4.7 \pm 0.6$ & $2.7 \pm 2.1$ & $2.3 \pm 0.3$ \\
\hline total & 32 & 29 & 21 & 18 & $3.3 \pm 1.6$ & $3.9 \pm 1.8$ & $2.6 \pm 1.0$ & $2.4 \pm 0.7$ \\
\hline \multicolumn{9}{|c|}{ Secondary dispersal } \\
\hline spontaneous & 6 & 0 & 5 & 0 & $1.6 \pm 0.9$ & - & $4.0 \pm 1.0$ & - \\
\hline breakup & 2 & 0 & 1 & 0 & 3.0 & - & $3.3 \pm 0.0$ & - \\
\hline total & 8 & 0 & 6 & 0 & $1.8 \pm 1.0$ & - & $3.9 \pm 0.9$ & - \\
\hline \multicolumn{9}{|l|}{ All dispersals } \\
\hline spontaneous & 34 & 24 & $23^{*}$ & 15 & $2.6 \pm 1.3$ & $3.7 \pm 2.1$ & $2.8 \pm 1.0$ & $2.4 \pm 0.8$ \\
\hline breakup & 6 & 5 & 3 & 3 & $4.7 \pm 2.1$ & $4.7 \pm 0.6$ & $2.9 \pm 1.7$ & $2.3 \pm 0.3$ \\
\hline total & 40 & 29 & 26 & 18 & $2.9 \pm 1.6$ & $3.9 \pm 1.8$ & $2.8 \pm 1.1$ & $2.4 \pm 0.7$ \\
\hline
\end{tabular}


Table 2 Generalised linear models of mean daily activity and daily distance travelled for eight African wild dogs which wore GPS-

collars both while dispersing and while resident. Each model also includes individual identity as a fixed effect (full model shown in Table S6).

\begin{tabular}{|c|c|c|c|c|c|c|}
\hline \multirow[b]{2}{*}{ Variable } & \multicolumn{3}{|c|}{ Mean daily activity } & \multicolumn{3}{|c|}{ Daily km travelled } \\
\hline & Estimate & $S E$ & $p$ & Estimate & $S E$ & $p$ \\
\hline \multicolumn{7}{|l|}{ Daytime (sunrise to sunset) } \\
\hline Maximum temperature $\left({ }^{\circ} \mathrm{C}\right)$ & -2.611 & 0.395 & $<0.001$ & - & - & - \\
\hline Moonlight previous night (full-moon-hour equivalents) & -1.838 & 0.188 & $<0.001$ & -0.106 & 0.018 & $<0.001$ \\
\hline Dispersing $v s$. resident & 5.858 & 2.228 & 0.009 & 1.401 & 0.229 & $<0.001$ \\
\hline \multicolumn{7}{|l|}{ Night time (sunset to sunrise) } \\
\hline Maximum temperature previous day $\left({ }^{\circ} \mathrm{C}\right)$ & 4.335 & 1.213 & $<0.001$ & 0.951 & 0.183 & $<0.001$ \\
\hline Moonlight (full-moon-hour equivalents) & 4.191 & 0.528 & $<0.001$ & 0.484 & 0.083 & $<0.001$ \\
\hline Dispersing $v s$. resident & 70.530 & 35.741 & 0.049 & 22.440 & 5.459 & $<0.001$ \\
\hline Dispersing*moonlight interaction & -1.366 & 0.583 & 0.019 & -0.324 & 0.090 & $<0.001$ \\
\hline Dispersing* temperature interaction & -2.602 & 1.296 & 0.045 & -0.861 & 0.197 & $<0.001$ \\
\hline
\end{tabular}


Table 3 Generalised linear models of mean daily activity and daily distance travelled for seven African wild dogs which wore GPScollars during pack formation as well as dispersal. Each model also includes individual identity as a fixed effect (full model shown in Table S8).

\begin{tabular}{lrrrrrrr}
\hline & \multicolumn{3}{c}{ Mean daily activity } & \multicolumn{3}{c}{ Daily km travelled } \\
Variable & Estimate & $S E$ & & $p$ & Estimate & $S E$ & $p$ \\
\hline Daytime (sunrise to sunset) & & & & & & & \\
Maximum temperature $\left({ }^{\circ} \mathrm{C}\right.$ ) & -2.410 & 0.724 & $<0.001$ & & - & - & - \\
Moonlight previous night (full-moon-hour equivalents) & -1.659 & 0.297 & $<0.001$ & -0.067 & 0.022 & 0.002 \\
Days since pack formation & -0.014 & 0.037 & 0.705 & -0.007 & 0.001 & $<0.001$ \\
Night time (sunset to sunrise) & & & & & & & \\
Moonlight (full-moon-hour equivalents) & 2.138 & 0.367 & $<0.001$ & 0.101 & 0.032 & 0.002 \\
Days since pack formation & -0.172 & 0.040 & $<0.001$ & -0.015 & 0.002 & $<0.001$ \\
\hline
\end{tabular}


Dispersal behaviour of African wild dogs in Kenya

\section{Supporting Information}

Rosie Woodroffe, Daniella Rabaiotti, D.K. Ngatia, Thomas R.C. Smallwood, Stefanie Strebel, and Helen M.K. O’Neill 
Table S1 Dispersal distances of African wild dogs, measured in three different ways. Each measure is reported only where data were available to calculate it (e.g., dispersal group OlP1 was lost before forming a new pack and so has no centroid or den dispersal distance).

\begin{tabular}{|c|c|c|c|c|}
\hline \multirow[t]{2}{*}{ Dispersal Group } & \multirow[t]{2}{*}{ Dispersal type } & \multicolumn{3}{|c|}{ Dispersal distance (km) } \\
\hline & & centroid & den & GPS-collar \\
\hline \multicolumn{5}{|l|}{ Females - natal } \\
\hline Croc2 & spontaneous & 64.1 & - & $315.2^{*}$ \\
\hline Kat2 & spontaneous & 16.7 & 7.9 & $43.4 \dagger$ \\
\hline Leb2 & breakup & 43.7 & - & $170.8^{*}$ \\
\hline Loi10 & spontaneous & 48.2 & 59.5 & \\
\hline Loi10a & spontaneous & 43.3 & - & \\
\hline Loi12 & spontaneous & 21.6 & 29.6 & \\
\hline Lol1 & spontaneous & 43.6 & 53.9 & \\
\hline Mug2 & spontaneous & 86.9 & 83.5 & \\
\hline OlP1 & spontaneous & - & - & $1,688.5^{*}$ \\
\hline Rat1 & spontaneous & 22.3 & 20.5 & \\
\hline Sos2 & spontaneous & 18.7 & - & \\
\hline Sos 7 & spontaneous & - & 13.8 & \\
\hline Tui2 & spontaneous & 30.9 & 35.9 & $957.2^{*}$ \\
\hline \multicolumn{2}{|l|}{ mean } & 40.0 & 38.1 & 635.0 \\
\hline \multicolumn{5}{|l|}{ Females - secondary } \\
\hline Leb3 & spontaneous & 2.0 & 9.2 & \\
\hline Nol1 & breakup & 27.7 & 20.5 & \\
\hline Tru1 & spontaneous & 32.2 & - & \\
\hline Sos1 & spontaneous & 7.2 & 4.8 & \\
\hline mean & & 17.3 & 11.5 & \\
\hline all females - mean & & 33.8 & 30.8 & 635.0 \\
\hline \multicolumn{5}{|l|}{ Males - all natal } \\
\hline Croc1 & spontaneous & 38.1 & 46.9 & $276.4^{*}$ \\
\hline Kam1 & breakup & 7.6 & & \\
\hline Leb1 & breakup & 45.4 & 51.1 & \\
\hline Leb1a & breakup & 83.0 & & \\
\hline Len1 & spontaneous & 65.8 & & \\
\hline Loi1 & spontaneous & 75.5 & 82.2 & \\
\hline Loi11 & breakup & 12.0 & 1.6 & $148.9 \dagger$ \\
\hline Loi4 & spontaneous & 5.1 & 6.9 & \\
\hline Loi5 & spontaneous & 46.3 & & \\
\hline Loi9 & spontaneous & 68.4 & & $295.7^{*}$ \\
\hline Rat2 & spontaneous & 18.8 & 27.5 & \\
\hline Sos 3 & spontaneous & 56.8 & & \\
\hline Sos5 & spontaneous & 9.7 & 17.8 & \\
\hline all males - mean & & 41.0 & 33.4 & 240.3 \\
\hline overall mean & & 37.2 & 31.8 & 487.0 \\
\hline
\end{tabular}

*long-distance disperser in Table S3; †short-distance disperser in Table S3. 
Table S2 Summary of 69 dispersal events, involving 63 individuals identified before dispersal and collared before, during or afterwards(eight GPS-collared during dispersal), in 44 dispersal groups.

\begin{tabular}{|c|c|c|c|c|c|c|c|c|c|}
\hline \multirow[b]{2}{*}{ individual } & \multirow[b]{2}{*}{ sex } & \multirow[b]{2}{*}{$\begin{array}{l}\text { dispersal } \\
\text { group }\end{array}$} & \multirow[b]{2}{*}{$\begin{array}{l}\text { dispersal } \\
\text { number }\end{array}$} & \multirow[b]{2}{*}{$\begin{array}{l}\text { dispersal } \\
\text { cause }\end{array}$} & \multirow{2}{*}{$\begin{array}{l}\text { dispersal } \\
\text { group } \\
\text { size }\end{array}$} & \multirow{2}{*}{$\begin{array}{l}\text { collared } \\
\text { at time of } \\
\text { dispersal? }\end{array}$} & \multicolumn{3}{|c|}{ GPS-collar data } \\
\hline & & & & & & & $\begin{array}{l}\text { resident } \\
\text { before }\end{array}$ & $\begin{array}{l}\text { during } \\
\text { dispersal }\end{array}$ & $\begin{array}{l}\text { resident } \\
\text { after }\end{array}$ \\
\hline WDF1 & $\mathrm{F}$ & Lol1 & natal & spontaneous & 4 & yes & - & - & - \\
\hline WDF2 & $\mathrm{F}$ & Lol1 & natal & spontaneous & 4 & yes & - & - & - \\
\hline WDF7 & $\mathrm{F}$ & Lol1 & natal & spontaneous & 4 & no & - & - & - \\
\hline \multirow[t]{2}{*}{ WDF8 } & $\mathrm{F}$ & Lol1 & natal & spontaneous & 4 & no & - & - & - \\
\hline & & Sos1 & secondary & spontaneous & 2 & yes & - & - & - \\
\hline WDF21 & $\mathrm{F}$ & Sos1 & natal & spontaneous & 2 & yes & - & - & - \\
\hline WDF26 & $\mathrm{F}$ & Pyr1 & secondary & spontaneous & 1 & yes & - & - & - \\
\hline WDF20 & $\mathrm{F}$ & Sos 2 & natal & spontaneous & NA & no & - & - & - \\
\hline WDF28 & $\mathrm{F}$ & Ten1 & natal & spontaneous & NA & yes & - & - & - \\
\hline WDM29 & M & Mug1 & natal & spontaneous & NA & yes & - & - & - \\
\hline WDM32 & M & Len1 & natal & spontaneous & NA & yes & - & - & - \\
\hline WDM34 & M & Sos3 & natal & spontaneous & 2 & yes & - & - & - \\
\hline WDF38 & $\mathrm{F}$ & Mug2 & natal & spontaneous & NA & yes & - & - & - \\
\hline WDF41 & $\mathrm{F}$ & Sos4 & natal & spontaneous & 1 & yes & - & - & - \\
\hline WDM51 & M & Sos 5 & natal & spontaneous & 4 & yes & - & - & - \\
\hline WDM56 & M & Sos5 & natal & spontaneous & 4 & no & - & - & - \\
\hline WDM57 & M & Sos 5 & natal & spontaneous & 4 & no & - & - & - \\
\hline WDF59 & $\mathrm{F}$ & Nol1 & secondary & breakup & 3 & yes & - & - & - \\
\hline & & Rat1 & natal & spontaneous & 4 & yes & - & - & - \\
\hline WDM60 & M & Rat2 & natal & spontaneous & 4 & yes & - & - & - \\
\hline WDM63 & M & Kam1 & natal & breakup & 5 & yes & - & - & - \\
\hline WDM64 & M & Rat2 & natal & spontaneous & 4 & yes & - & - & - \\
\hline WDM65 & M & Kam2 & natal & spontaneous & NA & yes & - & - & - \\
\hline WDF67 & $\mathrm{F}$ & Loi12 & natal & spontaneous & NA & no & - & - & - \\
\hline WDM68 & M & Loi1 & natal & spontaneous & 2 & yes & - & - & - \\
\hline WDF69 & $\mathrm{F}$ & Rat1 & natal & spontaneous & 4 & no & - & - & - \\
\hline WDF70 & $\mathrm{F}$ & Rat1 & natal & spontaneous & 4 & no & - & - & - \\
\hline & & Nol1 & secondary & breakup & 3 & yes & - & - & - \\
\hline WDM71 & M & Sos6 & natal & spontaneous & 4 & yes & - & - & - \\
\hline WDF72 & $\mathrm{F}$ & Sos7 & natal & spontaneous & 2 & no & - & - & - \\
\hline WDF79 & $\mathrm{F}$ & Loi2 & natal & spontaneous & 1 & yes & - & - & - \\
\hline WDM82 & M & Rat2 & natal & spontaneous & 4 & yes & - & - & - \\
\hline WDF83 & $\mathrm{F}$ & Rat3 & natal & spontaneous & 2 & yes & - & - & - \\
\hline WDM84 & M & Loi3 & natal & spontaneous & 2 & yes & - & - & - \\
\hline WDM85 & M & Loi3 & natal & spontaneous & 2 & yes & - & - & - \\
\hline WDM88 & M & Loi4 & natal & spontaneous & 9 & yes & - & - & - \\
\hline WDM89 & M & Loi5 & natal & spontaneous & 3 & yes & - & - & - \\
\hline WDM91 & M & Loi4 & natal & spontaneous & 9 & yes & - & - & - \\
\hline WDF92 & $\mathrm{F}$ & Loi6 & natal & spontaneous & 3 & yes & - & - & - \\
\hline WDM95 & M & Loi4 & natal & spontaneous & 9 & yes & - & - & - \\
\hline WDF96 & $\mathrm{F}$ & Loi7 & natal & breakup & 7 & yes & - & - & - \\
\hline WDM99 & M & Mou1 & natal & spontaneous & NA & yes & - & - & - \\
\hline WDM102 & M & Leb1 & natal & breakup & 4 & yes & - & - & - \\
\hline WDM103 & M & Leb1 & natal & breakup & 4 & yes & - & - & - \\
\hline WDF104 & $\mathrm{F}$ & Rat4 & natal & spontaneous & NA & yes & - & - & - \\
\hline WDF105 & $\mathrm{F}$ & Loi6 & natal & spontaneous & 3 & yes & - & - & - \\
\hline WDF106 & $\mathrm{F}$ & Leb3 & secondary & spontaneous & 1 & no & - & - & - \\
\hline WDM107 & M & Loi4 & natal & spontaneous & 9 & no & - & - & - \\
\hline WDF109 & $\mathrm{F}$ & Leb2 & natal & breakup & 4 & yes & no & yes & yes \\
\hline WDF110 & $\mathrm{F}$ & Leb2 & natal & breakup & 4 & yes & - & - & - \\
\hline WDM111 & M & Lois9 & natal & spontaneous & 3 & yes & yes & yes & yes* \\
\hline WDM112 & M & Tui1 & natal & spontaneous & NA & yes & - & - & - \\
\hline WDF113 & $\mathrm{F}$ & Loi10 & natal & spontaneous & 5 & yes & - & - & - \\
\hline WDF116 & $\mathrm{F}$ & Loi10 & natal & spontaneous & 5 & yes & - & - & - \\
\hline WDF117 & $\mathrm{F}$ & Loi7 & natal & breakup & 7 & yes & - & - & - \\
\hline WDM119 & M & Loi11 & natal & breakup & 5 & yes & yes & yes & yes \\
\hline WDF120 & $\mathrm{F}$ & Tui2 & natal & spontaneous & 5 & yes & yes & yes & yes \\
\hline & & Tru1 & secondary & spontaneous & 3 & no & - & - & - \\
\hline WDF121 & $\mathrm{F}$ & Tui2 & natal & spontaneous & 5 & yes & - & - & - \\
\hline & & Tru1 & secondary & spontaneous & 3 & yes & - & - & - \\
\hline WDM122 & M & Loi11 & natal & breakup & 5 & no & - & - & - \\
\hline WDF125 & $\mathrm{F}$ & Kat1 & natal & spontaneous & 3 & yes & - & - & - \\
\hline WDF126 & $\mathrm{F}$ & Kat2 & natal & spontaneous & 3 & yes & yes & yes & yes \\
\hline & & Tou1 & secondary & spontaneous & 1 & yes & - & - & - \\
\hline WDF128 & $\mathrm{F}$ & Kat2 & natal & spontaneous & 3 & yes & - & - & - \\
\hline WDM129 & M & Loi5 & natal & spontaneous & 3 & no & - & - & - \\
\hline WDF130 & $\mathrm{F}$ & OlP1 & natal & breakup & 3 & yes & yes & yes & no \\
\hline WDM136 & M & Croc1 & natal & spontaneous & 4 & yes & yes & yes & yes \\
\hline WDF137 & $\mathrm{F}$ & Croc2 & natal & spontaneous & 3 & yes & yes & yes & yes \\
\hline
\end{tabular}

*location data are available post-dispersal but activity data are not, due to safety concerns about downloading a large file from an aircraft in mountainous terrain. 
Table S3 - Generalised Linear Mixed Models (GLMMs) of dispersal age. Each model also includes dispersal group identity as a random effect. After adjusting for the effects of dispersal number (Model 1), variables describing sex and dispersal cause did not contribute significantly to model fit.

\begin{tabular}{lrrr}
\hline Variable & Estimate & SE & p \\
\hline Model 1 & & & \\
Dispersal number (secondary vs natal) & 1.458 & 0.335 & $<0.001$ \\
Model 2 & & & \\
Dispersal number (secondary vs natal) & 1.384 & 0.356 & $<0.001$ \\
Sex (male vs female) & -0.199 & 0.239 & 0.409 \\
Model 3 & & & \\
Dispersal number (secondary vs natal) & 1.476 & 0.338 & $<0.001$ \\
Dispersal cause (spontaneous vs breakup) & 0.191 & 0.293 & 0.496 \\
\hline
\end{tabular}

Table S4 - Poisson regression models of dispersal group size. After adjusting for the effects of individual age (Model 1), variables describing sex, dispersal number, and dispersal cause did not contribute significantly to model fit.

\begin{tabular}{|c|c|c|c|}
\hline Variable & Estimate & SE & $\mathbf{p}$ \\
\hline \multicolumn{4}{|l|}{ Model 1} \\
\hline$\overline{\text { Age of youngest member (ln-transformed) }}$ & -0.867 & 0.304 & 0.004 \\
\hline \multicolumn{4}{|l|}{ Model 2} \\
\hline$\overline{\text { Age of youngest member (ln-transformed) }}$ & -0.803 & 0.313 & 0.010 \\
\hline Sex (male vs female) & 0.165 & 0.196 & 0.400 \\
\hline \multicolumn{4}{|l|}{ Model 3} \\
\hline$\overline{\text { Age of youngest member (ln-transformed) }}$ & -0.734 & 0.360 & 0.042 \\
\hline Dispersal number (secondary vs natal) & -0.265 & 0.410 & 0.518 \\
\hline \multicolumn{4}{|l|}{ Model 4} \\
\hline Age of youngest member (ln-transformed) & -0.853 & 0.306 & 0.005 \\
\hline Dispersal cause (spontaneous vs breakup) & -0.413 & 0.218 & 0.059 \\
\hline
\end{tabular}

Table S5 - Generalised Linear Mixed Model (GLMM) of inter-birth interval. Pack identity is included as a random effect.

\begin{tabular}{lrrr}
\hline Variable & Estimate & SE & p \\
\hline Type of inter-birth interval & & & \\
resident to resident vs. before \& after spontaneous dispersal & -54.5 & 23.3 & 0.024 \\
before \& after breakup vs. before \& after spontaneous dispersal & 244.0 & 54.4 & $<0.001$ \\
\hline
\end{tabular}


Table S6 Generalised linear models of mean daily activity and daily distance travelled for eight African wild dogs which wore GPS-collars both while dispersing and while resident. This is the same model as the one shown in Table 2 of the main text, but showing effects of individual identity.

\begin{tabular}{|c|c|c|c|c|c|c|}
\hline \multirow[b]{2}{*}{ Variable } & \multicolumn{3}{|c|}{ Mean daily activity } & \multicolumn{3}{|c|}{ Daily km travelled } \\
\hline & Estimate & $S E$ & $p$ & Estimate & $S E$ & $p$ \\
\hline \multicolumn{7}{|l|}{ Daytime (sunrise to sunset) } \\
\hline Maximum temperature $\left({ }^{\circ} \mathrm{C}\right)$ & -2.611 & 0.395 & $<0.001$ & - & - & - \\
\hline Moonlight previous night (full-moon-hour equivalents) & -1.838 & 0.188 & $<0.001$ & -0.106 & 0.018 & $<0.001$ \\
\hline Dispersing $v s$. resident & 5.858 & 2.228 & 0.009 & 1.401 & 0.229 & $<0.001$ \\
\hline \multicolumn{7}{|l|}{ Individual identity } \\
\hline WDF120 vs WDF109 & -42.790 & 5.300 & $<0.001$ & 1.328 & 0.313 & $<0.001$ \\
\hline WDF126 vs WDF109 & -39.767 & 5.248 & $<0.001$ & -0.106 & 0.282 & 0.706 \\
\hline WDF130 vs WDF109 & -28.207 & 5.237 & $<0.001$ & 1.407 & 0.296 & $<0.001$ \\
\hline WDF137 vs WDF109 & -22.151 & 5.455 & $<0.001$ & 0.458 & 0.339 & 0.177 \\
\hline WDM111 vs WDF109 & -34.247 & 7.868 & $<0.001$ & -0.035 & 0.343 & 0.918 \\
\hline WDM119 vs WDF109 & -35.177 & 5.070 & $<0.001$ & 0.583 & 0.279 & 0.037 \\
\hline WDM136 vs WDF109 & -32.428 & 5.220 & $<0.001$ & -0.270 & 0.293 & 0.357 \\
\hline \multicolumn{7}{|l|}{ Night time (sunset to sunrise) } \\
\hline Maximum temperature previous day $\left({ }^{\circ} \mathrm{C}\right)$ & 4.335 & 1.213 & $<0.001$ & 0.951 & 0.183 & $<0.001$ \\
\hline Moonlight (full-moon-hour equivalents) & 4.191 & 0.528 & $<0.001$ & 0.484 & 0.083 & $<0.001$ \\
\hline Dispersing $v s$. resident & 70.530 & 35.741 & 0.049 & 22.440 & 5.459 & $<0.001$ \\
\hline Dispersing*moonlight interaction & -1.366 & 0.583 & 0.019 & -0.324 & 0.090 & $<0.001$ \\
\hline Dispersing* temperature interaction & -2.602 & 1.296 & 0.045 & -0.861 & 0.197 & $<0.001$ \\
\hline \multicolumn{7}{|l|}{ Individual identity } \\
\hline WDF120 vs WDF109 & 6.470 & 6.460 & 0.317 & 2.642 & 0.906 & 0.004 \\
\hline WDF126 vs WDF109 & 0.404 & 6.376 & 0.949 & 0.508 & 0.850 & 0.550 \\
\hline WDF130 vs WDF109 & 18.621 & 6.372 & 0.004 & 2.606 & 0.874 & 0.003 \\
\hline WDF137 vs WDF109 & 4.321 & 6.606 & 0.513 & 2.342 & 0.936 & 0.012 \\
\hline WDM111 vs WDF109 & 23.207 & 9.725 & 0.017 & 0.067 & 0.897 & 0.940 \\
\hline WDM119 vs WDF109 & 0.352 & 6.171 & 0.955 & 1.826 & 0.848 & 0.031 \\
\hline WDM136 vs WDF109 & 11.929 & 6.346 & 0.060 & 1.635 & 0.885 & 0.648 \\
\hline
\end{tabular}


Table S7 Comparisons of dispersal behaviour among long- and short-distance dispersers fitted with GPS-collars. Short-distance dispersers are defined as individuals which established a new territory overlapping their natal territory $(n=2)$, whereas long-distance dispersers either established territories further away $(n=5)$ or were lost far beyond their natal territory $(\mathrm{n}=1$; see Table S1). We compared the behaviour of these animals during dispersal by replacing the two-level (dispersing/resident) variable in the model shown in Table S6 with a three level (dispersing long distance/dispersing short distance/resident) variable; we here report the difference between the effects of long-and short-distance dispersal. We compared the behaviour of long- and short-distance dispersers after dispersal by adding a new two-level variable (long distance disperser/short distance disperser) to the model shown in Table S8; we here report the effects associated with this variable.

\begin{tabular}{lcccccc}
\hline & \multicolumn{3}{c}{ Mean daily activity } & \multicolumn{3}{c}{ Daily km travelled } \\
\cline { 2 - 7 } Variable & Estimate & $S E$ & $p$ & Estimate & $S E$ & $p$ \\
\hline Behaviour during long-distance vs short distance dispersal (c.f. Table S2) & & & & \\
\hline daytime & -12.441 & 7.418 & 0.094 & -0.637 & 0.840 & 0.449 \\
night time & -14.431 & 8.962 & 0.134 & -2.010 & 1.467 & 0.171 \\
Behaviour after long-distance vs short distance dispersal (c.f. Table S4) & & & \\
daytime & -2.991 & 3.427 & 0.383 & -0.243 & 0.279 & 0.384 \\
night time & 1.833 & 4.357 & 0.545 & -0.695 & 0.402 & 0.084 \\
\hline
\end{tabular}


Table S8 Generalised linear models of mean daily activity and daily distance travelled for seven African wild dogs which wore GPS-collars during pack formation as well as dispersal. This is the same model as the one shown in Table 3 of the main text, but showing effects of individual identity.

\begin{tabular}{|c|c|c|c|c|c|c|}
\hline \multirow[b]{2}{*}{ Variable } & \multicolumn{3}{|c|}{ Mean daily activity } & \multicolumn{3}{|c|}{ Daily km travelled } \\
\hline & Estimate & $S E$ & $p$ & Estimate & $S E$ & $p$ \\
\hline \multicolumn{7}{|l|}{ Daytime (sunrise to sunset) } \\
\hline Maximum temperature $\left({ }^{\circ} \mathrm{C}\right)$ & -2.410 & 0.724 & $<0.001$ & - & - & - \\
\hline Moonlight previous night (full-moon-hour equivalents) & -1.659 & 0.297 & $<0.001$ & -0.067 & 0.022 & 0.002 \\
\hline Days since pack formation & -0.014 & 0.037 & 0.705 & -0.007 & 0.001 & $<0.001$ \\
\hline \multicolumn{7}{|l|}{ Individual identity } \\
\hline WDF120 vs WDF109 & -47.895 & 5.431 & $<0.001$ & 1.174 & 0.326 & $<0.001$ \\
\hline WDF126 vs WDF109 & -34.834 & 6.157 & $<0.001$ & 0.323 & 0.296 & 0.275 \\
\hline WDF137 vs WDF109 & -10.493 & 8.390 & 0.212 & 0.159 & 0.685 & 0.816 \\
\hline WDM111 vs WDF109* & - & - & - & 0.058 & 0.323 & 0.859 \\
\hline WDM119 vs WDF109 & -44.616 & 5.190 & $<0.001$ & 0.243 & 0.279 & 0.384 \\
\hline WDM136 vs WDF109 & -39.645 & 5.259 & $<0.001$ & -0.150 & 0.275 & 0.585 \\
\hline \multicolumn{7}{|l|}{ Night time (sunset to sunrise) } \\
\hline Moonlight (full-moon-hour equivalents) & 2.138 & 0.367 & $<0.001$ & 0.101 & 0.032 & 0.002 \\
\hline Days since pack formation & -0.172 & 0.040 & $<0.001$ & -0.015 & 0.002 & $<0.001$ \\
\hline \multicolumn{7}{|l|}{ Individual identity } \\
\hline WDF120 vs WDF109 & -25.337 & 4.499 & $<0.001$ & 1.623 & 0.494 & 0.001 \\
\hline WDF126 vs WDF109 & -55.316 & 5.902 & $<0.001$ & -0.889 & 0.411 & 0.031 \\
\hline WDF137 vs WDF109 & -10.909 & 7.804 & 0.163 & -0.275 & 1.008 & 0.785 \\
\hline WDM111 vs WDF109* & - & - & - & -1.065 & 0.462 & 0.021 \\
\hline WDM119 vs WDF109 & -28.550 & 4.478 & $<0.001$ & 0.695 & 0.402 & 0.084 \\
\hline WDM136 vs WDF109 & -17.673 & 4.461 & $<0.001$ & 1.425 & 0.414 & $<0.001$ \\
\hline
\end{tabular}

*the last collar download for WDM111 was made by aircraft in a remote and mountainous area and post-dispersal activity data could not be downloaded for safety reasons. 

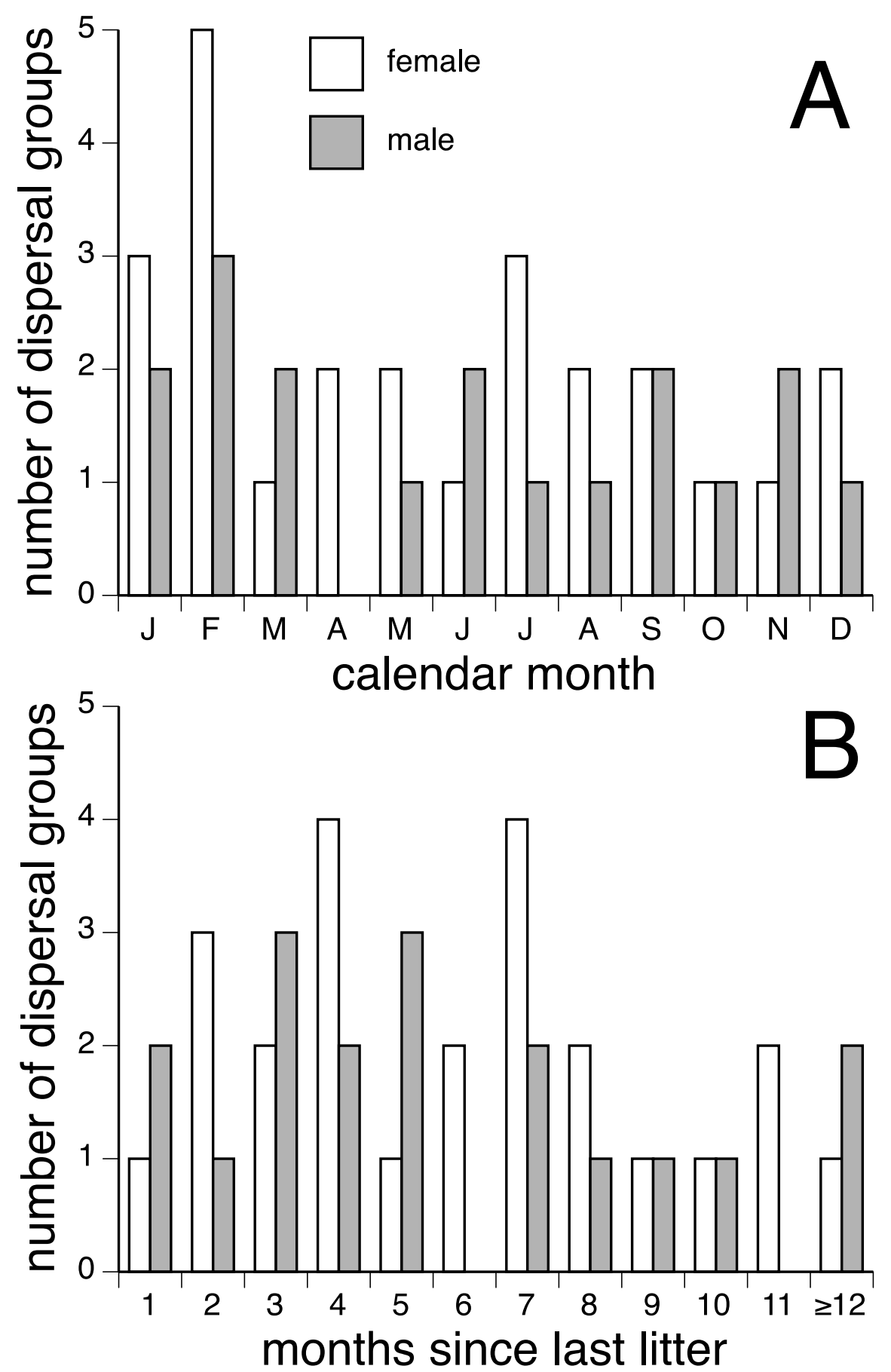

Figure S1 Timing of African wild dog dispersal relative to (A) calendar months, (B) time since the last litter in the origin pack 